Research Article

\title{
Carriage Rate of Coagulase Negative Staphylococci in a Rural Human Population with or without Companion Livestock
}

\author{
Sweta Jangra', Mukesh Sharma ${ }^{2}$, Anita Chakravarti ${ }^{3}$, Debasish Chattopadhya ${ }^{4}$ \\ ${ }^{1}$ Tutor, ${ }^{2}$ Assistant Professor, ${ }^{3}$ Professor and Head, ${ }^{4}$ Associate Professor, Department of Microbiology, SGT University, Gurugram, \\ Haryana, India.
}

DOI: https://doi.org/10.24321/0019.5138.201930

\section{I $\quad \begin{array}{lllll}\mathbf{N} & \mathbf{F} & \mathbf{O}\end{array}$}

\author{
Corresponding Author: \\ Debasish Chattopadhya, Department of \\ Microbiology, SGT University, Gurugram, \\ Haryana, India. \\ E-mail Id: \\ dchattopadhya27@gmail.com \\ Orcid Id: \\ https://orcid.org/0000-0002-4117-3050 \\ How to cite this article: \\ Jangra S, Sharma M, Chakravarti A, Chattopadhya \\ D. Carriage Rate of Coagulase Negative \\ Staphylococci in a Rural Human Population with \\ or without Companion Livestock. J Commun Dis \\ 2019; 51(4): 1-9.
}

Date of Submission: 2019-10-04

Date of Acceptance: 2020-01-28

\section{$\begin{array}{llllllll}\mathbf{A} & \mathbf{B} & \mathbf{S} & \mathbf{T} & \mathbf{R} & \mathbf{A} & \mathbf{C} & \mathbf{T}\end{array}$}

Background: The emergence of antibiotic resistance in Coagulase Negative Staphylococci (CoNS) in both humans and companion livestock has been recognized to be an issue of public health concern. There are limited studies reported to evaluate the risk of transmission of antibiotic resistant CoNS from companion livestock to their human owners.

Material \& Methods: A random of 200 households, 100 each with or without companion livestock were included in the study (sub-grouped as Sgr la and Sgr lb resp.). All the selected subjects were sampled from different anatomical sites, CoNS were identified by standard procedures and subjected to AST.

Results: Out of a total 400 and 440 samples from Sgr la and Sgr lb, 232 $(58 \%)$ and $162(37 \%)$ resp. showed positive isolation for CoNS with S.epidermidis as the most common isolated species. Two species of CoNS viz. S.scuiri and S.warneri were also isolated from Sgr la subjects alone. Methicillin resistance was found to be high among all the CoNS isolates. Resistance rates towards non $-\beta$ lactam antibiotics were found to be significantly higher among Sgr la compared to Sgr lb.

Conclusion: The present study suggests that transmission of various species as well as resistance genes can be possible from companion livestock to their owners. Hence human population in rural community with companion livestock should be routinely monitored for acquisition of antimicrobial resistance so as to prevent the further spread to human community.

Keywords: CoNS, Antimicrobial Resistance, Carriage Rate, Companion Livestock, Rural Population

\section{Introduction}

Coagulase-Negative Staphylococci (CoNS), considered as contaminants earlier, are now being recognized to be associated with many serious infections in human e.g. native valve endocarditis, peritonitis, surgical sites infections, prosthetic devices and shunt infections..$^{1,2}$ CoNS consist of 
a variety of staphylococcus species some of which such as S. epidermidis and S. haemolyticus colonize permanently or transiently at the anterior nares, skin and mucous membranes and act as source bacteremia and other infections. ${ }^{3}$ The situation is further complicated by emergence of resistance to common antimicrobial agents among them. ${ }^{4}$ While most of the reports on CoNS as human pathogens are hospital based, those on the prevalence of CoNS in a community are limited..$^{5,6}$ Determining the carriage rate of CoNS in a community, specially the multi-drug resistant strains, could reflect existence of the reservoir pool of such organisms in the community. ${ }^{7}$

In the rural community in North India majority of the population human beings are engaged in farming as profession. There are several risk factors for them that could be correlated for acquisition of drug resistant CoNS such as contact with animals carrying them due to indiscriminate use of antibiotics in animals. ${ }^{8}$ There are few studies on prevalence of CoNS in healthy companion animals from developed countries like the United States, where dogs and cats have been considered as companion animals. ${ }^{9,}{ }^{10}$ However in a developing country like India, the livestock e.g. buffaloes and cattle also represent companion animals in rural population due to sharing of common residential premises with humans. Some species of CoNS are known to be exclusively associated with animals. ${ }^{11}$ Therefore, search for such strains in human population with companion livestock could be indicative of their transmission probability from livestock to human population. The present study was undertaken to find out the carriage rate of CoNS, identification of species, their antibiogram pattern and possible risk factors for acquisition in a rural population with livestock as companion animal.

\section{Materials and Methods}

\section{Study Area}

The study was carried out in two villages in the district Gurugram, Haryana state, India with the population in the villages being predominantly farmers having livestock as companions sharing the same residential premises with that of the owner. Ethical clearance was obtained from independent institutional ethical committee for this study.

\section{Selection of Study Population}

- Selection of human subjects (grouped as Group I or Gr I): A random of 200 households, comprising of 100 each with or without companion livestock (cattle and buffalo) were selected for the survey. All the human subjects (ranging 2-6 members/household), regardless of age and sex, residing in two categories of households i.e. with or without companion livestock, grouped as subgroup la (Sgr la) and subgroup Ib(Sgr lb) subjects respectively were sampled.
- Selection of companion livestock (grouped as Group II or Gr II ): All the livestocks sharing residential premises with the Sgr la subjects (ranging 3-6 livestock/household) were selected for sampling.

- The selected human subjects, were provided patient information sheet and consent was obtained from them for the study and only those members consenting to participate in the study and agreed for sampling from themselves as well as from companion livestock were included.

\section{Exclusion Criteria}

The following categories of human subjects and companion animals were excluded from the study.

- History of antibiotics therapy, ongoing or within past 4 weeks.

- Any wound infection.

- Any major surgery in recent past (within 1 month).

- Close contacts with hospital environment.

\section{Collection of Demographic and Epidemiological Information}

Information regarding age, sex, level of education, number of companion livestocks and duration of their association were collected from the human subjects employing a predesigned proforma.

\section{Selection of Sites for Sampling}

Samples were taken from 5 anatomical sites viz. skin on hands, skin on feet, anterior nares, axilla and head in case of human subjects while in case of companion livestocks samples were taken from 4 anatomical sites viz. muzzle, udder, skin, and inner nares. ${ }^{12}$

\section{Sample Collection and Transport}

\section{Sample Collection}

\section{Human Subjects}

- Skin of hands and feet: Cotton swabs, moistened with sterile physiological saline, were used, one for each hand. The swab on each hand was swiped on the dorsum of hand to cover all the fingers, including finger-rings (if worn by the participants), tip of nails and inter-digital spaces. The swabs from each hand were then pooled into one tube containing transport medium. Similar procedure was followed for swabbing dorsum of feet covering areas on toes, toe nails and inter-digital spaces. ${ }^{13}$

- Anterior nares: The swab, premoistened with sterile normal saline was inserted approximately $2 \mathrm{~cm}$ into both the nares, turn by turn and rotated against the anterior nasal mucosa for 3 seconds.

- Axilla: Skin on the axillary area on both sides were 
rubbed in a rotating manner to cover up to a $5 \mathrm{~cm} \times 5 \mathrm{~cm}$ area approximately using separate swab for each side.

\section{Companion Livestock}

Swab samples from companion livestock were collected by the same procedure as for human individuals with the help of their handlers from the following anatomical sites.

- Muzzle: Inside both the nostrils (5 to $10 \mathrm{~cm}$ deep).

- Skin: Area on the skin between the thigh on both sides and udder.

- Perineum: Area on the skin in the groin area.

- Udder: Surface of udder in an area of $5 \mathrm{~cm} \times 5 \mathrm{~cm}$ approx.

\section{Sample Transport}

The collected swab samples were transported to the Microbiology laboratory in Phosphate Buffer Saline $(\mathrm{pH}$ 7.2-7.4) as transport medium with icepack within 1-2 hours.

\section{Processing of Samples and Identification of CoNS Isolates}

Each swab sample was streaked on $5 \%$ sheep blood agar and inoculated plates were incubated aerobically at $37^{\circ} \mathrm{C}$ overnight (18-24 hrs). Presumptive staphylococcal colonies were stained with gram stain and were subjected to catalase test and further evaluated for confirmation of coagulase production by tube coagulase test using human plasma. ${ }^{14} \mathrm{All}$ resulting coagulase negative staphylococcal colonies were further identified to species level using the Vitek 2c gram positive identification cards according to manufacturer's directions (Biomerieux India Pvt. Ltd.).

\section{Antimicrobial Susceptibility Testing}

Antimicrobial susceptibility of CoNS isolates were determined by Kirby Bauer agar disc diffusion method recommended by Clinical and Laboratory Standard Institutes (CLSI, 2018). Antimicrobial agents tested and their respective strengths were as follows:

Penicillin (10 U), Amikacin $(30 \mu \mathrm{g})$, Erythromycin $(15 \mu \mathrm{g})$, Clindamycin $(2 \mu \mathrm{g})$, Tetracycline $(30 \mu \mathrm{g})$, cefoxitin $(30 \mu \mathrm{g})$, cefuroxime $(30 \mu \mathrm{g})$, Vancomycin $(30 \mu \mathrm{g})$, Ampicillin $(10 \mu \mathrm{g})$, Ciprofloxacin $(5 \mu \mathrm{g})$. Methicillin resistance was detected by using Cefoxitin (30 $\mu \mathrm{g}$ ) disc as a surrogate marker for methicillin resistance. ${ }^{15}$

\section{Statistical Analysis}

All the data collected from selected population were analyzed by using Chi-square test which is an accepted tool for categorical variables. Association of positivity rate among sub parameters of Sgr la subjects were determined by using Chi square for trend. ${ }^{16}$

\section{Result}

Out of 100 households each in Sgr la and Sgr Ib, total of 400 and 440 human subjects respectively were sampled while all the companion livestock (sharing same residential premises with Sgrl a human subjects), totaling to 320 animals were sampled.

Table I.Carriage rate of CoNS in human subjects with or without companion livestock in relation to various parameters

\begin{tabular}{|c|c|c|c|c|c|c|}
\hline \multirow{3}{*}{\multicolumn{2}{|c|}{$\begin{array}{c}\text { Demographic and } \\
\text { epidemiological parameter }\end{array}$}} & \multicolumn{4}{|c|}{ Positivity rate for CoNS } & \multirow{4}{*}{$\begin{array}{l}\text { Statistical analysis } \\
\chi^{2}=7.40, p=0.007^{*}\end{array}$} \\
\hline & & \multicolumn{2}{|c|}{ Sgr la } & \multicolumn{2}{|l|}{ Sgr lb } & \\
\hline & & $\begin{array}{l}\text { No of subjects } \\
(n=400)\end{array}$ & No (\%) & $\begin{array}{c}\text { No of subjects } \\
(n=440)\end{array}$ & No (\%) & \\
\hline \multirow{3}{*}{$\begin{array}{l}\text { Age group } \\
\text { (years) }\end{array}$} & $0-15$ & 76 & $19(25)$ & 110 & $49(11.1)$ & \\
\hline & $16-45$ & 223 & $179(80)$ & 209 & $64(30.6)$ & $\chi^{2}=108, p=0.000^{*}$ \\
\hline & $>45$ & 101 & $34(33.6)$ & 121 & $49(30)$ & $\chi^{2}=1.09, p=N S(0.12)^{*}$ \\
\hline \multirow[b]{2}{*}{ Sex } & Male & 208 & $108(51.9)$ & 194 & $87(45.9)$ & $\chi^{2}=2.01, p=N S(0.15)^{*}$ \\
\hline & Female & 192 & $92(47.9)$ & 246 & $130(53)$ & $\chi^{2}=1.04, p=N S(0.36)^{*}$ \\
\hline \multirow{3}{*}{$\begin{array}{l}\text { Companion livestock } \\
\text { size }\end{array}$} & 1 & 46 & $10(21.7)$ & \multirow{3}{*}{\multicolumn{2}{|c|}{ NA }} & \multirow{3}{*}{$\chi^{2}=63.4, p<0.01^{* *}$} \\
\hline & $2-5$ & 54 & $15(27.7)$ & & & \\
\hline & $>5$ & 300 & 207 (69) & & & \\
\hline \multirow{3}{*}{$\begin{array}{c}\text { Duration of association } \\
\text { with companio } \\
\text { livestocks (years) }\end{array}$} & $0-5$ & 90 & $35(38.8)$ & \multirow{3}{*}{\multicolumn{2}{|c|}{ NA }} & \multirow{3}{*}{$\chi^{2}=23.4, p<0.001^{* *}$} \\
\hline & $6-10$ & 110 & $58(52.7)$ & & & \\
\hline & $>10$ & 200 & $139(69.5)$ & & & \\
\hline
\end{tabular}

NA-Not Applicable.

* Statistical comparison between Sgr la and Sgr Ib for the same parameter.

**Chi square trend herd size and duration of association with increase in positivity rate. 
Table 2.Carriage rate of CoNS according to anatomical sites among human subjects with or without companion livestock and companion livestock

\begin{tabular}{|c|c|c|c|c|c|c|c|c|}
\hline \multirow{3}{*}{$\begin{array}{c}\text { Sites } \\
\text { (Human } \\
\text { subjects) }\end{array}$} & \multirow{3}{*}{$\begin{array}{c}\text { Sites } \\
\text { (companion } \\
\text { livestock) }\end{array}$} & \multicolumn{4}{|c|}{ Group I Human subjects } & \multicolumn{2}{|c|}{$\begin{array}{c}\text { Group II Companion } \\
\text { Livestock }\end{array}$} & \multirow{3}{*}{$\begin{array}{l}\text { Statistical } \\
\text { Analysis* }\end{array}$} \\
\hline & & \multicolumn{2}{|c|}{ Sgr la } & \multicolumn{2}{|c|}{ Sgr Ib } & \multirow{2}{*}{$\begin{array}{c}\text { No of } \\
\text { samples }\end{array}$} & \multirow{2}{*}{$\begin{array}{l}\text { Carriage } \\
\text { rate No } \\
(\%)\end{array}$} & \\
\hline & & $\begin{array}{c}\text { No of } \\
\text { samples }\end{array}$ & \begin{tabular}{|c|} 
Carriage \\
rate No (\%)
\end{tabular} & $\begin{array}{c}\text { No of } \\
\text { samples }\end{array}$ & $\begin{array}{c}\text { Carriage } \\
\text { rate No (\%) }\end{array}$ & & & \\
\hline Axilla & & 400 & $240(60)$ & 440 & $160(36.3)$ & \multicolumn{2}{|c|}{ NA } & $\chi^{2}=46 ; p=0.00$ \\
\hline Skin (foot) & & 400 & $208(52)$ & 440 & $148(33.5)$ & \multicolumn{2}{|c|}{ NA } & $\chi^{2}=28 ; p=0.00$ \\
\hline $\begin{array}{l}\text { Anterior } \\
\text { nares }\end{array}$ & & 400 & $160(40)$ & 440 & $132(30)$ & \multicolumn{2}{|c|}{ NA } & $\begin{array}{c}\chi^{2}=9.23 \\
p=N S(0.12)\end{array}$ \\
\hline \multirow[t]{4}{*}{ Skin (hands) } & Skin & 400 & $320(80)$ & 440 & $220(50)$ & 320 & $80(25)$ & $\chi^{2}=82 ; p=0.00$ \\
\hline & Muzzle & \multicolumn{2}{|r|}{ NA } & \multicolumn{2}{|r|}{ NA } & 320 & $250(78)$ & NA \\
\hline & Perineum & \multicolumn{2}{|r|}{ NA } & \multicolumn{2}{|c|}{ NA } & 320 & $112(35)$ & NA \\
\hline & Udder & \multicolumn{2}{|r|}{ NA } & \multicolumn{2}{|c|}{ NA } & 320 & $211(66.5)$ & NA \\
\hline \multicolumn{2}{|c|}{ Total } & 1600 & $928(58)$ & 1760 & $660(37.5)$ & 1280 & $653(51.1)$ & $\chi^{2}=141 ; p<0.001$ \\
\hline
\end{tabular}

NA=Not Applicable

*Statistical comparison between human subjects belonging to the groups Sgr la and Sgr Ib.

A total of 232 subjects out of 400 subjects in Sgr la and 162 out of 440 subjects in Sgr lb yielded positive isolation for CoNS with the prevalence rate of $58 \%$ and $37 \%$ respectively. Subjects in age group of 16-45 years showed higher CoNS positivity rate compared to other age groups in Sgr la subjects whereas no statistically difference was observed in the carriage rate among subjects of Sgr Ib belonging to various age groups.

No statistically significant difference was observed in positivity rate between males and females belonging to Sgr la and Sgr Ib subjects. Positivity rate was found to be higher in the families who had a greater number of companion livestocks $(>5)$ with them. CoNS positivity was found to be higher in the families who reported living with companion animals for more than 10 years compared to those with lesser duration of association (Table 1). A total of 163 out of 320 companion livestock sampled in Gr Il yielded positive isolation for CoNS (data not shown in table).
Isolation rate of CoNS among humans from various anatomical sites were found to be significantly higher in Sgr la compared to the corresponding anatomical sites in Sgr Ib except from anterior nares. Difference in isolation rate between Sgr la and Sgr Ib subjects was more marked for samples collected from the skin on hands. Companion livestocks showed a higher isolation rate of CoNS from muzzle area compared to other anatomical sites (Table 2).

S.epidermidis was found to be the most prevalent species among CoNS isolates from humans regardless of association with companion livestocks in this study. Relative carriage rate of various species of CoNS among companion livestocks was found to be similar as that of the human subjects associated with them However two species viz, S.scuiri and S.warneri which are predominantly associated with animals were also isolated from Sgr la individuals which were associated with handling of companions livestock (Table 3).

Table 3.Relative distribution of various Species of CoNS among human subjects (Sgr la and Sgr lb) and companion livestock (Gr II)

\begin{tabular}{|c|c|c|c|}
\hline \multirow{2}{*}{ Species } & \multicolumn{2}{|c|}{ Gr I (Human) } & Gr II (Companion livestock) \\
\cline { 2 - 4 } & Sgr la $(\mathbf{n}=928)$ & Sgr Ib $(\mathbf{n}=660)$ & $136(32.9 \%)$ \\
\hline S.epidermidis & $250(26.9 \%)^{*}$ & $230(34.8 \%)^{*}$ & $74(18 \%)$ \\
\hline S.hemolyticus & $111(11.9 \%)$ & $94(14.2 \%)$ & $61(15 \%)$ \\
\hline S.hominis & $222(23.9 \%)$ & $143(21.6 \%)$ & $-\cdots$ \\
\hline S.capitis & $150(16.2 \%)$ & $193(29.2 \%)$ & $78(19 \%)$ \\
\hline S.scuiri & $111(11.9 \%)$ & --- & $61(15.1 \%)$ \\
\hline S.warneri & $84(9 \%)$ & --- & \\
\hline
\end{tabular}

*Significantly higher rate $(\mathrm{p}<0.05)$ compared to other species in the same group (Sgr la and Sgr Ib). 
Table 4.Antibiotic resistance profile of the CoNS isolates

\begin{tabular}{|c|c|c|c|c|c|c|c|c|c|c|c|c|}
\hline \multirow{2}{*}{\multicolumn{2}{|c|}{ Group }} & \multirow{3}{*}{$\begin{array}{c}\begin{array}{c}\text { Source of } \\
\text { CoNS isolate }\end{array} \\
928\end{array}$} & \multicolumn{10}{|c|}{ No (\%) Resistant strains } \\
\hline & & & \multirow{2}{*}{$\begin{array}{c}\mathbf{P} \\
538 \\
(58) \\
\end{array}$} & \multirow{2}{*}{$\begin{array}{c}\mathbf{E} \\
139 \\
(15)\end{array}$} & \multirow{2}{*}{$\begin{array}{c}\text { CD } \\
167 \\
(18) \\
\end{array}$} & \multirow{2}{*}{$\begin{array}{c}\text { TC } \\
232 \\
(25) \\
\end{array}$} & \multirow{2}{*}{$\begin{array}{c}\text { CX } \\
372 \\
(40)\end{array}$} & \multirow{2}{*}{$\begin{array}{c}\text { CXM } \\
334 \\
(36) \\
\end{array}$} & \multirow{2}{*}{$\begin{array}{l}\text { Cip } \\
186 \\
(20) \\
\end{array}$} & \multirow{2}{*}{$\begin{array}{c}\text { Amc } \\
47 \\
(5) \\
\end{array}$} & \multirow{2}{*}{$\begin{array}{c}\text { Amp } \\
61 \\
(6.5) \\
\end{array}$} & \multirow{2}{*}{$\begin{array}{c}\text { Ak } \\
19 \\
(2.5)\end{array}$} \\
\hline Gr I & Sgr la & & & & & & & & & & & \\
\hline & Sgr Ib & 660 & $\begin{array}{l}240 \\
(40)\end{array}$ & $\begin{array}{l}30 \\
(5)\end{array}$ & $\begin{array}{l}30 \\
(5)\end{array}$ & $\begin{array}{l}42 \\
(7)\end{array}$ & $\begin{array}{c}60 \\
(10)\end{array}$ & $\begin{array}{l}120 \\
(20)\end{array}$ & $\begin{array}{l}24 \\
(4) \\
\end{array}$ & 0 & 0 & 0 \\
\hline \multirow{2}{*}{\multicolumn{2}{|c|}{$\begin{array}{l}\text { Statistical } \\
\text { analysis* }\end{array}$}} & $x^{2}$ & 72.00 & 44 & 64 & 93 & 187 & 59 & 90 & 14 & 19 & 10 \\
\hline & & $\mathrm{p}$ & 0.00 & 0.00 & 0.00 & 0.00 & 0.00 & 0.00 & 0.00 & 0.00 & 0.00 & 0.00 \\
\hline \multicolumn{2}{|c|}{ Gr II (Animal) } & 410 & $\begin{array}{l}287 \\
(70) \\
\end{array}$ & $\begin{array}{l}103 \\
(25)\end{array}$ & $\begin{array}{l}115 \\
(28)\end{array}$ & $\begin{array}{l}164 \\
(40) \\
\end{array}$ & $\begin{array}{c}174 \\
(42.5) \\
\end{array}$ & $\begin{array}{c}82 \\
(20)\end{array}$ & $\begin{array}{c}125 \\
(30.5) \\
\end{array}$ & $\begin{array}{l}22.5 \\
(5.5) \\
\end{array}$ & $\begin{array}{c}47 \\
(11.5)\end{array}$ & $\begin{array}{l}20 \\
(5)\end{array}$ \\
\hline \multirow{2}{*}{\multicolumn{2}{|c|}{$\begin{array}{l}\text { Statistical } \\
\text { analysis ** }\end{array}$}} & $x^{2}$ & 17.4 & 19 & 17, & 40 & 0.6 & 70 & 70 & 0.05 & 0.9 & 8.1 \\
\hline & & $\mathrm{p}$ & 0.00 & 0.00 & 0.00 & 0.00 & $\begin{array}{l}\text { NS } \\
(0.4)\end{array}$ & 0.00 & 0.00 & $\begin{array}{l}\text { NS } \\
(0.8)\end{array}$ & $\begin{array}{c}\text { NS } \\
(0.7)\end{array}$ & $\begin{array}{c}\text { NS } \\
(0.05)\end{array}$ \\
\hline
\end{tabular}

P-Penicillin, E-Erythromycin, CD-Clindamycin, TC-Tetracycline, CX-Cefoxitine, CXM-Cefuroxime, Cip-Ciprofloxacin, Amc-Amoxyclave, AmpAmpicillin, Ak-Amikacin.

*Statistical comparison between human subjects with (Sgr la) and without companion livestocks (Sgr lb).

**Statistical analysis between Sgr la (human subjects) and Gr II.

Methicillin Resistant CoNS (MRCoNS) rate among isolates from Sgr la were found to be higher compared to Sgr Ib (Table 4). while among companion livestock's (Gr. II) prevalence of MRCoNS was also found to be high. Sgr la humans showed statistically significant higher rate of resistance towards non $\beta$ lactam antibiotics including erythromycin, clindamycin, ciprofloxacin as compared to Sgr Ib humans. Companion livestocks group II carried a higher resistance to penicillin along with an overall resistance to the non $\beta$ lactam antimicrobials whereas the resistance pattern was same for human subjects of Sgr la. Regarding the non $\beta$ lactam antibiotics the resistance rates were found to be higher among companion livestocks similar to the human subjects belonging to Sgr la compared to Sgr Ib human subjects (Table 4).

\section{Discussion}

Rural human community associated with animals are at increased risk of exposure to many zoonotic pathogens e.g., Staphylococcus, Streptococcus, Escherichia coli, Shigella spp. following which they could also become carriers and can spread infections to the community. ${ }^{17}$ In the rural community in India companion livestock are considered as family members and close proximity or direct animal contact can be seen in many households (companion livestocks). This leads to the potential risk of transmission of a multitude of pathogenic microorganisms, including multidrug-resistant bacteria, between companion livestock and their human owners. ${ }^{18,19}$ Higher prevalence of CoNS among human subjects in the present study associated with companion livestock compared to those without such association suggest their possible acquisition from companion livestock sharing the same premises.

High carriage rate of CoNS in the age group between 1545 years could be related to greater involvement of this particular age group in day to day care of the companion livestock e.g. feeding, milking bathing etc. This was further evident from the lack of association of CoNS positivity with any particular age in sub group of human subjects without companion livestocks. Shinde et al in their study on adoption of improved dairy practices by dairy farmers also found that majority $(65 \%)$ of the respondents were in middle age group (31-45 years), followed by young age group up to 30 years (20\%) and remaining and remaining $15 \%$ in old age group ( 46 years and above)..$^{20}$ There are numerous studies in India that showed that both male and females are equally engaged in routine activities involving care of livestock with woman spending about two hours a day on animal rearing activities associated with the care of companion livestock supporting our observation of equal distribution of CoNS positivity in both sexes. ${ }^{21,22}$ Based on a data from labour inputs, from rural Haryana and West Bengal it was shown that in each rural households, in India it is reported that predominantly women perform all the day to day activities related to caring, feeding, cleaning, health and production of livestock. ${ }^{23}$ while some activities such as vaccinations, deworming, grazing, purchase of fodder and medicines, and taking animals to the dispensary are performed predominantly by male members, providing equal chances for acquisition of pathogenic organisms among both male and females from animals. ${ }^{24}$ According to a study by Fang et al the carriage rate of staphylococcus in 
large-scale farmers (those who were in animal farming for a long time) was found to be significantly higher than that in small-scale farmers suggesting an association between herd size and duration with companion livestock with CoNS as observed in the present study. ${ }^{25}$

There are several studies reported on various species of CoNS associated with various anatomical sites. Vanessa M et al found S.epidermidis to be the most common species isolated from the nares, perineum, inguinal skin, axillae and interdigital skin of human beings in her study. ${ }^{26}$ Another study by Rogers et al on human subjects with dogs as companion animal showed S.epidermidis to be the most common (52\%) species of CoNS isolated predominantly form the nasal cavity of dogs with the similar species of CoNS species isolated from similar sites in humans. ${ }^{27}$ Animals are found to be common reservoirs of CoNS and carry CoNS on their skin, noses, udders, upper alimentary and urogenital tract and intestinal tract and thus may be transmitted to human due to contact with those animal by hands during routine activities like milking, bathing etc. ${ }^{7}$ High isolation rate of staphylococci from hands in our study is an expected observation as hands are reported to be principle vector for transmitting microorganisms between pets and human subjects.

S.epidermidis was found to be the most prevalent species among all the CoNS isolates that can cause significant disease in this study. A study by Ibrahim et al also showed the predominant species of CoNS isolated and identified from various body sites were S.epidermidis (54.7\%) while other species of CoNS were isolated less frequently i.e., S.haemolyticus $23.4 \%$, S.hominis $5.8 \%$ followed by $S$. lugdunensis in $4 \%$, S. capitis in $3.6 \%$ and S. saprophyticus in $3.1 \%{ }^{28}$ The other salient observations in the present study was that some species of CoNS e.g., S.scuiri and S.warneri that are reported to be predominantly associated with animals were also found in human subjects associated with them (Sgr la) in the present study strengthening further the possibility of transmission of these CoNS species from their companion livestock. ${ }^{29}$

Transmission of resistance from animals to humans can take place through a variety of routes while the food-borne route probably is the most important route for enteric bacterial pathogens, such as Salmonella enterica, Campylobacter coli/jejuni and Yersinia enterocolitica, for other resistant pathogens, e.g., MRSA direct contact between animal and humans may be the major route of transmission (e.g. MRSA CC398). Researchers have shown that transfer of multiple resistant Staphylococcus intermedius and quinolone resistant Campylobacter jejuni can occur between humans and dogs living in the same household). ${ }^{30}$ Growth promoters are used in livestock as they are used as food animals although use of antimicrobials for growth promotions is not a prevalent practice in India where livestock are not used as food animals in the country. However, in India there is little regulation on the use of drugs in veterinary sector for various ailments in animals resulting in the indiscriminate use of antibiotics in companion livestocks that might lead to development of high antimicrobial resistance in them. ${ }^{31}$ Bovine mastitis is an expensive disease affecting lactating cattle's in India. Some studies from India reported that the incidence of sub clinical mastitis ranged from 19.2-83\% in cows. About 70-80\% economic loss has been attributed due to sub clinical mastitis. ${ }^{32}$ In addition nearly all dairy cows receive intramammary infusions of prophylactic doses of antibiotics following each lactation to prevent and control future mastitis-primarily with penicillin's, cephalosporins, or other beta-lactam drugs. ${ }^{33}$ Antimicrobial resistance of mastitis pathogens has received a lot of interest in the past few years causing heavy economic burden in dairy sector attributable to bacteria resistant to routinely used antibiotics. ${ }^{34}$ There is very little data available on resistance among CoNS in healthy human population although there are numerous reports on antimicrobial resistance among various species of CoNS as carrier associated with various human infections. An epidemiological study of staphylococci among healthy humans (without companion livestocks) and its molecular characterization showed MRCoNS rate $54.2 \%$ along with S.epidermidis as their most common species among all CoNS isolates. ${ }^{35}$ Whereas the prevalence of MR-CoNS carriage among adult Americans were found to be $51 \%$ in 2006 and $47 \%$ in 2008 with most prevalent species being S.epidermidis, which contrasts with previous community-based surveys, where the reported rates ranged from 11 to $30 \%$ for methicillin resistance. ${ }^{36}$ Adabi et al. showed $71.7 \%$ of school students in india harbored CoNS in their nasal cavity with $16.7 \%$ among the isolates being MRCoNS. ${ }^{37}$ Jonathan $\mathrm{H}$ et al. from Leeds, UK in their study showed most of the healthy individuals carrying CoNS, the organisms were resistant to penicillin, tetracycline and erythromycin and the most commonly species encountered was S.epidermidis. ${ }^{38}$ The antibiotics that were found to be most commonly co-resistant with CoNS in our study was tetracycline. This is in contrast to the study by Elena $\mathrm{G}$ et al. who reported a high rate of methicillin resistance, $81.3 \%$ with all MRCoNS isolates that were methicillin resistant also resistant to tetracycline However in the present study we found lower degree of association between MRCoNS and tetracycline with $25 \%$ of CoNS were co-resistant to tetracycline, showed that $74 \%$ of clinically healthy dogs harbored CoNS in their nares, from which $23.7 \%, 16.9 \%, 5.1 \%$ were resistant to penicillin, erythromycin and tetracycline respectively. ${ }^{39}$ Huber et al. from Switzerland showed S.sciuri as most prevalent species among all the CoNS isolates from which nasal MRCoNS rate was observed as $67 \%$ and $60.2 \%$ among pig farmers and 
veterinarians respectively that was comparatively higher than the present study. ${ }^{40}$

Admittedly however we could not perform molecular analysis of the CoNS isolated from human and companion animals to provide more convening evidence of transmission animal - human Nevertheless along with an higher isolation rate among human subjects with companion livestock compared to those without companion animals, isolation of two species among the farmer population i.e., S.scuiri and S.warneri that is identical to human subjects associated with them provide evidence that human population in association with companion animals are at increased risk for acquisition of multidrug resistant CoNS that may further spread horizontally in community. To the best of our knowledge there is not much literature on carriage of CoNS in healthy population in association with livestock in India.

\section{Conclusion}

The present study suggests that transmission of various species as well as resistance genes can be possible from companion livestock to their owners associated with activities related to care of them. Hence human population in rural community with companion livestock should be routinely monitored for acquisition of antimicrobial resistance so as to prevent the further spread to human community.

\section{Conflict of Interest: None}

\section{References}

1. Wisplinghoff $H$, Bischoff T, Tallent $S M$, Seifert $H$, Wenzel RP, Edmond MB. Nosocomial bloodstream infections in US hospitals: analysis of 24,179 cases from a prospective nationwide surveillance study. Clin Infect Dis 2004; 39(3): 309-317. Available from: https://academic.oup. com/cid/article/39/3/309/351413 [PubMed/ Google Scholar].

2. Otto M. Staphylococcus epidermidis - the 'accidental' pathogen. Nat Rev Microbial 2004; 7(8): 555-567. [PubMed/ Google Scholar].

3. Heikens E, Fleer A, Paauw A, Florijn A, Fluit AC. Comparison of genotypic and phenotypic methods for species-level identification of clinical isolates of Coagulase-negative staphylococci. J Clin Microbiol 2005; 43: 2286-2290. Available from: https://jcm.asm.org/ content/43/5/2286.long [PubMed/ Google Scholar].

4. Diekema D, Pfaller M, Schmitz F, et al. Infections due to Staphylococcus species: frequency of occurrence and antimicrobial susceptibility of isolates collected in the United States, Canada, Latin America, Europe, and the Western Pacific region for the SENTRY Antimicrobial Surveillance Program. Clin Infect Dis 2001; 32: 114132. Available from: https://academic.oup.com/cid/ article/32/Supplement_2/S114/275412 [PubMed/
Google Scholar].

5. Milisavljevic V, Wu F, Cimmoti J, Haas J, Della-Latta P, Larson E et al. Genetic relatedness of Staphylococcus epidermidis from infected infants and staff in the neonatal intensive care unit. Am J Infect Control 2005; 33(6): 341-347. Available from: https://www. ajicjournal.org/article/S0196-6553(05)00167-7/fulltext [PubMed/ Google Scholar].

6. Khashu M, Osiovich $H$, Henry D, Al Khotani A, Solimano A, Speert DP. Persistent bacteremia and severe thrombocytopenia caused by coagulasenegative Staphylococcus in a neonatal intensive care unit. Pediatrics J Dis 2006; 117(2): 340-348. Available from: https://pediatrics.aappublications. org/content/117/2/340.long?sso=1\&sso_redirect_co unt $=1 \&$ nfstatus $=401 \&$ nftoken $=00000000-0000-0000$ 0000-000000000000\&nfstatusdescription=ERROR\%3 a+No+local+token [PubMed/ Google Scholar].

7. Gomez E, Torres C, Lozano C, Zarazaga M. High diversity of Staphylococcus aureus and Staphylococcus pseudintermedius lineages and toxigenic traits in healthy pet-owning household members. Underestimating normal house- hold contact? Comp Immunol Microbiol Infect Dis 2013; 36: 11-14. Available from: https:// www.sciencedirect.com/science/article/abs/pii/ S0147957112001063?via\%3Dihub [PubMed/ Google Scholar].

8. Department of Agriculture (US) Fort Collins (CO): USDA, Animal and Plant Health Inspection Service, Veterinary Services, National Animal Health Monitoring System; 2008. Dairy Part III: Reference of dairy cattle health and management practices in the United States, 2007.

9. Sing A, Tuschak C, Hörmansdorfer S. Methicillin-resistant Staphylococcus aureus in a family and its pet cat. N Eng J Med 2008; 358(11): 1200-1201. Available from: https:// www.nejm.org/doi/full/10.1056/NEJMc0706805?url_ ver=Z39.88-2003\&rfr_id=ori\%3Arid\%3Acrossref. org\&rfr_dat=cr_pub\%3Dpubmed [PubMed/ Google Scholar].

10. Morris D, Rook K, Shofer F, Rankin SC. Screening of Staphylococcus aureus, Staphylococcus intermedius, and Staphylococcus schleiferi isolates obtained from small companion animals for antimicrobial resistance: a retrospective review of 749 isolates (2003-04). Vet Dermatol 2006; 17: 332-337. Available from: https:// onlinelibrary.wiley.com/doi/abs/10.1111/j.13653164.2006.00536.x [PubMed/ Google Scholar].

11. Nagase N, Sasaki A, Yamashita K, Shimizu A, Wakita $Y$, Kitai $S$ et al. Isolation and species distribution of staphylococci from animal and human skin. J Vet Med Sci 2002; 64(3): 245-250. Available from: https://www. jstage.jst.go.jp/article/jvms/64/3/64_3_245/_article [PubMed/ Google Scholar]. 
12. Roberson JR, Fox LK, Hancock D, Gay JM, Besser TE. Ecology of Staphylococcus aureus Isolated from various sites on dairy farms. J Dairy Sci 1994; 77(11): 33543364. [PubMed/ Google Scholar].

13. Paul R, Das NK, Dutta R, Banerjee AK. Bacterial contamination of the hands of doctors: A study in the medicine and dermatology wards. Ind J Dermatol Venerol Leprol 2011; 77(3): 307-313. Available from: http://www.ijdvl.com/article.asp?issn=0378-6323; ye ar=2011; volume=77; issue=3; spage=307; epage=313; aulast=Paul [PubMed/ Google Scholar].

14. Mackie T, Collee J, McCartney J. Mackie and McCartney practical medical microbiology. $13^{\text {th }}$ ed., Churchill Livingstone Elsevier. 1989. 70-80.

15. Clinical Laboratory Standard Institute (CLSI). Performance Standards for Antimicrobial Susceptibility Testing; Twenty-seventh Informational Supplement. M100-S27, CLSI. Wayne, Pennsylvania, USA. 2018.

16. Kirkwood BR, Sterne JAC. Essential medical statistics. $2^{\text {nd }}$ ed. Blackwell, Oxford, United Kingdom. 2003; 476.

17. Levy S, Fitz G, Macone A. Spread of antibiotic resistance plasmids from chicken to chicken and from chicken to man. Nature 1976; 260: 40-42. Available from: https:// www.nature.com/articles/260040a0.

18. Wieler LH, Ewers C, Guenther S, Walther B, LübkeBecker A. Methicillin-resistant staphylococci (MRS) and extended-spectrum beta-lactamases (ESBL)-producing Enterobacteriaceae in companion animals: Nosocomial infections as one reason for the rising prevalence of these potential zoonotic pathogens in clinica samples. Int J Med Microbiol 2011; 301(8): 635-641. Available from: https://www.sciencedirect.com/science/article/ abs/pii/S1438422111000956?via\%3Dihub [PubMed/ Google Scholar].

19. Walther B, Hermes J, Cuny C, Wieler LH, Vincze S, Abou Elnaga $Y$ et al. Sharing more than friendship - nasal colonization with Coagulase-Positive Staphylococci (CPS) and co-habitation aspects of dogs and their owners. PLoS One 2012; 7: e35197. Available from: https://journals.plos.org/plosone/article?id=10.1371/ journal.pone.0035197 [PubMed/ Google Scholar].

20. Shinde VG, Sangle GK, Dikle RN. Adoption of improved dairy practices by dairy farmers. Maharashtra. J Ext Edu 1998; 17: 144-151. [Google Scholar].

21. Nataraju MS. Proceedings of National Symposium on women in Agriculture. UAS, Bangalore. 2007.

22. Shakunthala S. Women agriculture and rural development. New India Publishing Agency, New Delhi. 2009. Available from: https://www.nipabooks.com/ info/9788189422998/women-in-agriculture-and-ruraldevelopment.

23. Sethuraman G, Naidu S. International encyclopedia of agricultural science and technology. Mittal Publications,
New Delhi, India. 2018.

24. Fang HW, Chiang PH, Huang YC. Livestock-associated methicillin-resistant Staphylococcus aureus ST9 in pigs and related personnel in Taiwan. PLoS One 2014; 19(2): 112-120. Available from: https://journals.plos.org/ plosone/article?id=10.1371/journal. pone.0088826 [PubMed/ Google Scholar].

25. Vanessa M, Nicola J, Gina P, Caroline EC, Stephen $\mathrm{S}$, McEwan $\mathrm{N}$ et al. Antimicrobial resistance and characterization of staphylococci isolated from healthy Labrador retrievers in the United Kingdom. BMC Vet Res. 2014; 10: 17. Available from: https://bmcvetres. biomedcentral.com/articles/10.1186/1746-6148-10-17 [PubMed/ Google Scholar].

26. Rogers KL, Rupp ME, Fey PD. The presence of ICA ADBC is detrimental to the colonization of human skin by Staphylococcus epidermidis. Appl Environ Microbiol 2008; 74(19): 6155-6157. Available from: https://aem. asm.org/content/74/19/6155.long [PubMed/ Google Scholar].

27. Kloos WE, Zimmerman RJ, Smith RF. Preliminary studies on characterization and distribution of Staphylococcus and Micrococcus species on animal skin. App/ Environ Microbiol 1976; 31(1): 53-59. Available from: https:// aem.asm.org/content/31/1/53.long [PubMed/ Google Scholar].

28. Ibrahim A, Mazhar S, Emad H, Khudairat S, Sarosiekf K. Prevalence and antimicrobial susceptibility pattern of coagulase-negative staphylococci (CoNS) isolated from clinical specimens in Northern of Jordan. Iran J Microbiol 2015; 7(6): 294-301. [PubMed/ Google Scholar].

29. Grice EA, Kong H, Renaud G, Young AC, Bouffard GG, Blakesley RW et al. A diversity profile of the human skin microbiota. Genome Res 2008; 18(7): 1043-050. [PubMed/ Google Scholar].

30. Guardabassi L, Loeber ME, Jacobson A. Transmission of multiple antimicrobial-resistant Staphylococcus intermedius between dogs affected by deep pyoderma and their owners. Vet Microbiol 2004; 98(1): 23-27. Available from: https://www.sciencedirect.com/ science/article/pii/S0378113503003584?via\%3Dihub [PubMed/ Google Scholar].

31. Mellon M, Benbrook C, Benbrook KL. Hogging it estimates of antimicrobial abuse in Livestock. Union of Concerned Scientists, Cambridge, UK. 2001, 7-9.

32. Dua, K. Incidence, etiology and estimated economic losses due to mastitis in Punjab and in India - An update. Ind Dairyman 2001; 53: 41-48. [Google Scholar].

33. Singh B, Kumar R. Antimicrobial susceptibility of coagulase negative Staphylococci isolates from suspected cases of bovine subclinical mastitis in parts of Bundelkhand region. Asian Pac J Health Sci 2018; 
5(4): 100-107. Available from: http://www.apjhs.com/ pdf/15-Antimicrobial-susceptibility-of-coagulasenegative-Staphylococci-isolates-from-suspected-casesof-bovine-subclinical-mastitis-in-parts-of-Bundelkhandregion.pdf.

34. Verma $H$, Rawat $S$, Sharma N, Jaiswal V, Singh R. Prevalence, bacterial etiology and antibiotic susceptibility pattern of bovine mastitis in Meerut. J Ent and Zool Stud 2018; 6(1): 706-709. Available from: https://pdfs.semanticscholar.org/ e4df/23d4758752321f77e2f730be3117e6d5ea0d.pdf.

35. Mohammad I, Mohammadi A, Rezvan M, Khorshidi A, Piroozmand A, Mousavi SGA et al. Molecular characteristics of nasal carriage methicillin-resistant coagulase negative staphylococci in school students. Jundishapur J Microbiol 2015; 8: e18591. [PubMed/ Google Scholar].

36. Ruppe E, Barbier F, Mesli Y, Maiga A, Cojocaru R, Benkhalfat $M$ et al. Diversity of staphylococcal cassette chromosome mec structures in methicillin-resistant Staphylococcus epidermidis and Staphylococcus haemolyticus strains among outpatients from four countries. Antimicrob Agents Chemother 2009; 53(2): 442-449. Available from: https://aac.asm.org/ content/53/2/442.long [PubMed/ Google Scholar].

37. Adabi MIM, Mohiri R, Khorshidi A, et al. Molecular characteristics of nasal carriage methicillin- resistant coagulase negative staphylococci in school students. Jundishapur J Microbiol 2015; 8(6): 251-280. [PubMed/ Google Scholar].

38. Jonathan H, Cove E, Eady A et al. Skin carriage of antibiotic resistant coagulase negative staphylococci in untreated subjects. J Antimicrob Chemother 1990; 25: 459-469. [PubMed/ Google Scholar].

39. Chah KF, Gómez-Sanz E, Nwanta JA, Asadu B, Agbo IC, Lozano $C$ et al. Methicillin-resistant coagulase-negative staphylococci from healthy dogs in Nsukka, Nigeria. Braz J Microbiol 2014; 45(1): 215-220. [PubMed/ Google Scholar].

40. Huber $\mathrm{H}$, Koller S, Giezendanner $\mathrm{N}$, et al. Prevalence and characteristics of methicillin-resistant Staphylococcus aureus in humans in contact with farm animals, in livestock, and in food of animal origin, Switzerland. Euro Surveill 2012; 15: e19542. [PubMed/ Google Scholar]. 